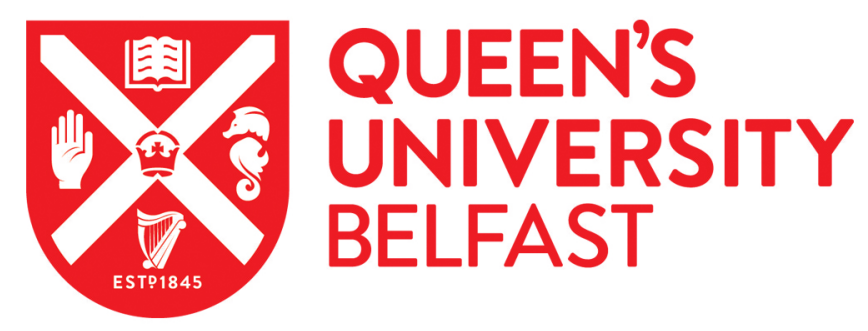

\title{
How Outcomes Are Defined in Clinical Trials of Mechanically Ventilated Adults and Children
}

\author{
Blackwood, B., Clarke, M., McAuley, D. F., McGuigan, P. J., Marshall, J. C., \& Rose, L. (2014). How Outcomes \\ Are Defined in Clinical Trials of Mechanically Ventilated Adults and Children. American Journal of Respiratory \\ and Critical Care Medicine, 189(8), 886-893 . https://doi.org/10.1164/rccm.201309-1645PP
}

Published in:

American Journal of Respiratory and Critical Care Medicine

Document Version:

Peer reviewed version

Queen's University Belfast - Research Portal:

Link to publication record in Queen's University Belfast Research Portal

\section{Publisher rights}

Originally Published in: Blackwood, B, Clarke, M, McAuley, DF, McGuigan, PJ, Marshall, JC \& Rose, L 2014, 'How Outcomes Are Defined in Clinical Trials of Mechanically Ventilated Adults and Children' American Journal of Respiratory and Critical Care Medicine, vol 189, no. 8, pp. 886-893., 10.1164/rccm.201309-1645PP

Copyright $(\odot) 2015$ by the American Thoracic Society

The final publication is available at http://www.atsjournals.org/doi/abs/10.1164/rccm.201309-1645PP\#.VWcSnM9VhBc

\section{General rights}

Copyright for the publications made accessible via the Queen's University Belfast Research Portal is retained by the author(s) and / or other copyright owners and it is a condition of accessing these publications that users recognise and abide by the legal requirements associated with these rights.

\section{Take down policy}

The Research Portal is Queen's institutional repository that provides access to Queen's research output. Every effort has been made to ensure that content in the Research Portal does not infringe any person's rights, or applicable UK laws. If you discover content in the Research Portal that you believe breaches copyright or violates any law, please contact openaccess@qub.ac.uk. 
1. Title: How outcomes are defined in clinical trials of mechanically ventilated adults and children

2. Bronagh Blackwood ${ }^{1}$, Mike Clarke ${ }^{2}$, Danny F McAuley ${ }^{1,3}{ }^{3}$, Peter J McGuigan ${ }^{3}$, John C Marshall ${ }^{4}$, Louise Rose ${ }^{4,5}$

3. ${ }^{1}$ Centre for Infection and Immunity, School of Medicine, Dentistry and Biomedical Sciences, Queen's University Belfast, Northern Ireland

${ }^{2}$ Centre for Public Health and Medical Research Council All Ireland Hub for Trials Methodology Research, School of Medicine, Dentistry and Biomedical Sciences, Queen's University Belfast, Northern Ireland

${ }^{3}$ Regional Intensive Care Unit, Royal Hospitals, Belfast Trust, Northern Ireland

${ }^{4}$ Li Ka Shing Knowledge Institute, St. Michael's Hospital, University of Toronto, Canada

${ }^{5}$ Lawrence S. Bloomberg Faculty of Nursing, University of Toronto; Provincial Centre of Weaning Excellence, Toronto East General Hospital; Mount Sinai Hospital, Toronto, Canada

4. Corresponding author: Bronagh Blackwood

Address: Centre for Infection and Immunity, Health Sciences Building, 97 Lisburn

Road, BT9 7AE, Northern Ireland

Email: b.blackwood@qub.ac.uk; Tel: +44 289097 2616; Fax: +44 2890972671

5. Author contributions: $B B, L R, D M c A$, and $M C$ have been involved in the conception and design of the study; $B B, P M c G$, and $L R$ have been involved in data acquisition and data extraction; $B B, L R, D M C A, J M$ and $M C$ have been involved in analysis and interpretation of the data; all authors have contributed to writing the article prior to submission.

6. Running title: How outcomes are defined in ventilation trials

7. No sources of support

8. Descriptor number 4.4 (Clinical Trials in Critical Care Medicine)

9. Body of the manuscript, 2258 words; abstract, 180 words

10. Scientific Knowledge on the Subject: International standards for trial registration call for sufficient detail on outcomes measured in clinical trials. Analyses of clinical trial outcomes documented in intervention reviews and trial databases indicate a lack of sufficient detail to aid comparison and synthesis of findings.

What this Study adds to the Field: Ventilation outcomes are not well defined and outcome time point measures are not consistent among trials. The outcomes reported generally fell into a number of domains that suggests the possibility of generating a core outcome set. 


\section{Abstract}

Systematic reviews have considerable potential to provide evidence-based data to aid clinical decision-making. However there is growing recognition that trials involving mechanical ventilation lack consistency in the definition and measurement of ventilation outcomes, creating difficulties in combining data for meta-analyses. To address the inconsistency in outcome definitions, international standards for trial registration and clinical trial protocols published recommendations, effectively setting the 'gold standard' for reporting trial outcomes. In this Critical Care Perspective, we review the problems resulting from inconsistent outcome definitions and inconsistent reporting of outcomes (outcome sets). We present data highlighting the variability of the most commonly reported ventilation outcome definitions. Ventilation outcomes reported in trials over the last six years typically fall into four domains: measures of ventilator dependence; adverse outcomes; mortality; and resource utilization. We highlight the need first, for agreement on outcome definitions and second, for a minimum core outcome set for trials involving mechanical ventilation. A minimum core outcome set would not restrict trialists from measuring additional outcomes, but would overcome problems of variability in outcome selection, measurement and reporting thereby enhancing comparisons across trials.

Keywords: core outcome measures; critical care trials; systematic reviews 


\section{Background}

Many interventions applied in the critically ill influence the duration of mechanical ventilation. Measures of ventilator dependence, such as duration of ventilation, are frequently used as primary and secondary outcomes. However, variations in outcome definitions lead to differences in estimates of treatment effects and in a systematic review this 'artefactual difference' may dilute the real effect (1). As such, it is highly desirable that standardized outcome definitions are used in trials examining interventions likely to affect duration of mechanical ventilation. This will enable treatment effects to be compared in an unbiased, reliable and robust manner.

Consistency in the measurement and reporting of trial outcomes is lacking. Williamson and colleagues noted that the most accessed and cited Cochrane reviews in 2009 all described inconsistencies in trial outcomes (2). Two recent systematic reviews of the effectiveness of protocolized weaning highlighted inconsistencies in measurement time points for ventilation outcomes $(3,4)$. Current international standards for trial registration (CONSORT, WHO registry) and the recent SPIRIT 2013 recommendations for writing clinical trial protocols stress that investigators should report the specific measurement variable and time frame for each outcome measure when registering trials (5-7). However, analysis of a cohort of records from the clinicaltrials.gov database indicated that $36 \%$ of trials registered a domain only and lacked definition of the specific measure, metric used or method of aggregation of results. (8). Furthermore, outcomes included in trial protocols are not always reported in trial publications $(9,10)$. 
In addition to the need for consistency in outcome definitions, Williamson and colleagues called for the development and use of core outcome sets (2), defined as an "agreed, standardized collection of outcomes measured and reported in all trials for a specific clinical area" (11). Agreement on a core outcome set should avoid problems associated with selective reporting of outcomes. The COMET (Core Outcome Measures in Effectiveness Trials) database has registered more than 260 references of planned work in developing core outcome sets and among them there are three studies exploring ventilation outcomes; long-term outcomes in acute respiratory failure; and rehabilitation following critical illness (12).

Little is known about how ventilation outcomes are defined and measured. To investigate this we sought to: first, identify trials involving mechanically ventilated adults and children that reported ventilation outcomes and describe how these outcomes were reported; and second, explore how trials specifically evaluating ventilation interventions reported ventilation outcomes and whether these might reveal a core outcome set.

\section{Review process}

We included trials published in the top ranked journals between January 2007 and December 2012 in general medicine (New England Journal of Medicine; Lancet; Journal of American Medical Association; Pediatrics) and critical care journals (American Journal of Respiratory and Critical Care Medicine; Critical Care Medicine; Intensive Care Medicine; Pediatric Critical Care Medicine). We specifically chose top ranked journals because of the 
likelihood of locating high quality trial reports. Rankings were based on the impact factors in the ISI Web of Knowledge, Journal Citation Reports 2011, Thomson Reuters. Our review only included randomized controlled trials involving adults or children receiving invasive mechanical ventilation and measuring outcomes pertaining to the duration of ventilation and its discontinuation. Three authors (BB, $L R, P M c G)$ divided the journals and independently searched, screened and extracted data. Titles and abstracts of papers in the journals were reviewed: full texts including supplementary material, published protocols or protocol registrations of all potentially relevant trials were retrieved. Details of the trials' aims, primary and secondary outcome measures and their definitions were extracted onto pre-piloted data extraction forms (see online data supplement, appendix 1). These forms were reviewed by the three authors to confirm inclusion: a fourth author (DMcA) acted as arbitrator.

\section{Results}

We included 66 reports of randomized trials (13-78) and associated documentation (59 trial registrations; 34 electronic supplementary materials; 13 published protocols) (Figure 1). Interventions addressed management of ventilation; sedation; physiotherapy; nutrition; renal/fluid management; medications and infection prevention. The 66 trials reported 30 different primary outcomes. Primary outcomes reported by more than 1 trial and secondary outcomes reported by more than 10 trials are shown in Figure 2.

Nine ventilation outcomes were reported across included trials reflecting measures of ventilator dependence or occurrence of events (typically adverse outcomes) (Table 1). 
Duration of ventilation was the most commonly reported outcome yet only 12 trials (25\%) provided a definition $(20,24,30,32,35,42-44,61,64,71,73)$ with substantial variation in time point measures. Twenty-five trials reported ventilator-free days as an outcome, 9 (36\%), $(18,19,23,51,53,62,63,72,73)$ provided no definition and variable start and end points were reported in the $16(64 \%)$ providing a definition $(24,26,31,45,50,52,54,57$, $58,65,66,68-70,72,76$ ) there were variable start and end points (Table 2). Three trials reporting weaning duration as a secondary outcome $(24,62,76)$ and only one provided a definition (24). When reintubation was reported as a trial outcome (4 trials), follow-up was measured at 24 -hours $(73), 48$-hours $(49,61)$ or 7 -days $(32)$. When reintubation was recorded as an adverse event ( 4 trials) $(31,40,55,71)$, the follow-up period within which this was measured was not provided.

\section{Outcomes reported in trials specifically evaluating a ventilation intervention}

Twelve trials tested a ventilation intervention including sedation and ventilation weaning methods (20, 30, 31, 43, 44, 49, 68); ventilator modes $(27,78)$; automated systems to facilitate ventilator weaning $(61,64)$; and early non-invasive ventilation following invasive ventilation (32). Primary and secondary outcomes reported in these trials are presented in Figure 3. Outcome measures reflected four domains; measures of ventilator dependence (e.g. duration of ventilation, duration of weaning, separation potential); adverse outcomes (e.g. VAP, reintubation, self extubation); mortality and survival outcomes (e.g. survival, ICU mortality, hospital mortality); and resource utilization (e.g. ICU LOS, hospital LOS, clinical workload). 
There was considerable variation in measuring primary outcomes. Ventilation trials reported either duration of mechanical ventilation or ventilator-free days, but not both. Start and endpoints are shown in Table 3. In secondary outcomes, mortality was reported for different follow up periods that included: $\operatorname{ICU}(20,49,68,78)$; hospital $(20,68,78)$; 28 -day $(31,64)$; 30-day (30); 90-day (31); and prior to ventilator separation potential and extubation (61). One trial did not define the follow up period (27) and one trial did not measure mortality (43). Two trials measured survival, at 1-year (31) and at an undefined time point (32).

\section{Discussion}

We found substantial variation in the outcome sets used. Outcome definitions differed between trials, often measuring different time points and different follow up periods. Furthermore, a large number of trials lacked detail in their outcome definitions.

It is important to highlight the effect related to the competing risk of death in using duration of ventilation as an outcome measure. Various statistical methods have tried to address this issue. Egleston and colleagues(79) point out that by using a basic approach of examining outcomes in survivors only it is possible that a harmful intervention will increase mortality in a vulnerable population. These remaining healthier survivors may have a reduced duration of ventilation giving the impression that the intervention has a beneficial effect. (79) Therefore it is important to consider the duration of ventilation as an outcome in the context of mortality. Measuring ventilator-free days (i.e. a composite outcome of mortality and duration of ventilation) is one method to address competing risks. (80) Our work has demonstrated that ventilator-free days are often poorly defined or not reported. 
Cause specific hazard models that fail to take into account the competing event (death) results in the patient being censored from the analysis and may falsely make the intervention appear beneficial. (81) When a sub-distribution hazard model is employed patients are not censored despite the occurrence of the competing event. When events are mutually exclusive such as death or unassisted breathing and discharge home a parametric mixture survival model may be the most appropriate method to determine the true effect of an intervention. (82)

The issue of competing risk is complex and does not just apply to mortality. An intervention intended to reduce the duration of mechanical ventilation may potentially lead to complications making it unclear whether the treatment causes the complication or results in more patients being alive to develop the complication. Statistical approaches such as cause specific hazard, cumulative incidence function and event-free survival are used to detect the true effect of an intervention. However, their ability to do so varies depending on whether the competing risk is affected in the same or opposite manner to the primary event being studied.(83) Regardless of these issues our finding of variability in mechanical ventilation outcome measures is important.

The outcome 'duration of mechanical ventilation' was reported by $73 \%$ of all trials and was measured from either intubation or initiation of ventilation (which may or may not occur simultaneously). It is generally interpreted as intubation and initiation of mechanical ventilation occurring on ICU admission. However, initiation may occur in the Operating Room or Emergency Department and the start time point may be difficult to obtain or 
inconsistently recorded. Furthermore, some trials reported randomization as the start point for 'duration of mechanical ventilation'. Firstly, the criteria for randomization vary between trials. Secondly, enrollment in some trials, for example, investigating weaning methods, are dependent upon physician assessment and are prone to bias. Finally, randomization may be delayed by the process of gaining consent, with consent windows up to 24 hours.

We found the end time point for measuring duration of mechanical ventilation was reported as either 'free from mechanical ventilation' or extubation. Free from mechanical ventilation was defined as either freedom from invasive ventilation or both invasive and non-invasive ventilation. Timing of extubation may be influenced by organizational issues such as workload and staff availability $(84,85)$. These organizational issues may vary widely between institutions and across trials. This wide variability in outcome definitions regarding start and end points of mechanical ventilation will not be problematic within a trial provided both arms are equally affected. However, it may lead to systemic variations when comparing trials, highlighting the need for agreed outcome definitions.

In the 12 trials specifically evaluating a ventilation intervention, there was also time point variation in secondary outcomes. When reporting mortality, it is reasonable to choose a longer duration of follow up when delayed effects are expected, such as in ARDS or severe sepsis (86). However, consensus on duration of follow up is required if trials are to be compared. Length of stay (ICU and hospital) was frequently measured as a secondary outcome. Length of stay is an important healthcare resource utilization outcome. However, it has limitations, particular in comparing trials across countries with different healthcare 
funding models and resource availability. Furthermore, contextual differences in end of life care practices may also affect duration of ventilation and length of stay.

Although this paper is the first to provide data showing substantial variation in outcome definitions in ventilation trials, it is not the first to call for improvements in standardizing outcomes in critical care trials. A workshop convened by the National Heart, Lung and Blood Institute (87) recommended standardization in describing and collecting endpoints to facilitate meta-analyses of acute lung injury trials; and a Society of Critical Care Medicine stakeholder conference (88) highlighted the necessity of gaining consensus on a standard set of outcome measures for long term outcomes following ICU discharge.

Our analysis indicates that outcomes reported in trials of ventilation interventions typically measure outcomes in a number of domains: measures of ventilator dependence; adverse outcomes; mortality and survival outcomes; and resource utilization. For ICU patients, being free from ventilation and survival are clearly important outcomes, but length of stay may not be. Longer term outcomes such as cognitive and physical function and quality of life are often under reported. $(87,88)$ However, the effects of critical illness impacts on patients long after hospital discharge and these longer term outcomes are increasingly being recognized as being important by investigators. (89-91) The optimal duration of long term follow-up remains to be determined.

The common domains that are addressed give rise to the possibility of obtaining agreement on outcome definitions and a core outcome set. A core outcome set would not restrict trialists from measuring additional outcomes, but would overcome problems of variability in 
outcome selection, measurement and reporting thereby enhancing valid comparisons across trials. To address this, we are undertaking a study that will use the Delphi technique to achieve international consensus on core outcome definitions and a core outcome set for use in trials involving mechanical ventilation (http://www.cometinitiative.org/studies/details/292?result=true). We will liaise closely with the International Forum for Acute Care Trialists (InFACT) and the Delphi panel will draw upon relevant stakeholders including patient groups, professional societies, clinical trial groups, and industry.

\section{Limitations}

Our search for trials was restricted to a short, but recent, time period and a small number of journals. It does not provide a full comprehensive overview of ventilation outcomes in trials across a longer time period and a wider range of journals; however, we are confident that we have presented sufficient data to demonstrate significant variability in outcome reporting in recent trials accepted for publication in high impact journals.

\section{Conclusion}

We show substantial variation in the choice of outcome measures and their definition in randomized trials evaluating interventions likely to influence the duration of ventilation. We anticipate the recent SPIRIT 2013 statement (7) outlining guidance for reporting clinical trial protocols will help investigators provide clear definitions enabling more appropriate comparisons. Expert consensus on, and implementation of, standardized outcome 
definitions and core outcome sets is fundamental to reducing bias when comparing effects across trials. 


\begin{tabular}{|c|c|c|c|c|}
\hline Outcome & $\begin{array}{l}\text { No of } \\
\text { trials }\end{array}$ & $\begin{array}{l}\text { Reported as } \\
\text { primary }\end{array}$ & $\begin{array}{l}\text { Reported as } \\
\text { adverse event }\end{array}$ & $\begin{array}{l}\text { Definition } \\
\text { provided } \\
\mathbf{N}(\%) \\
\end{array}$ \\
\hline \multicolumn{5}{|l|}{$\begin{array}{l}\text { Measures of ventilation } \\
\text { dependence }\end{array}$} \\
\hline Duration of ventilation & 48 & 9 & - & $12(25 \%)$ \\
\hline Ventilator-free days & 25 & 4 & - & $16(64 \%)$ \\
\hline Weaning time & 3 & - & - & $1(33 \%)$ \\
\hline $\begin{array}{l}\text { Time to separation } \\
\text { potential }\end{array}$ & 1 & 1 & - & $1(100 \%)$ \\
\hline \multicolumn{5}{|l|}{ Occurrence of events } \\
\hline Reintubation & 8 & 2 & 4 & $4(50 \%)$ \\
\hline Extubation failure & 4 & 1 & 1 & $2(50 \%)$ \\
\hline Use of post extubation & 4 & - & 3 & $1(25 \%)$ \\
\hline \multicolumn{5}{|l|}{ NIV } \\
\hline Weaning failure & 1 & 1 & - & $1(100 \%)$ \\
\hline Successful extubation & 1 & - & - & 0 \\
\hline
\end{tabular}

Key: NIV, non-invasive ventilation 


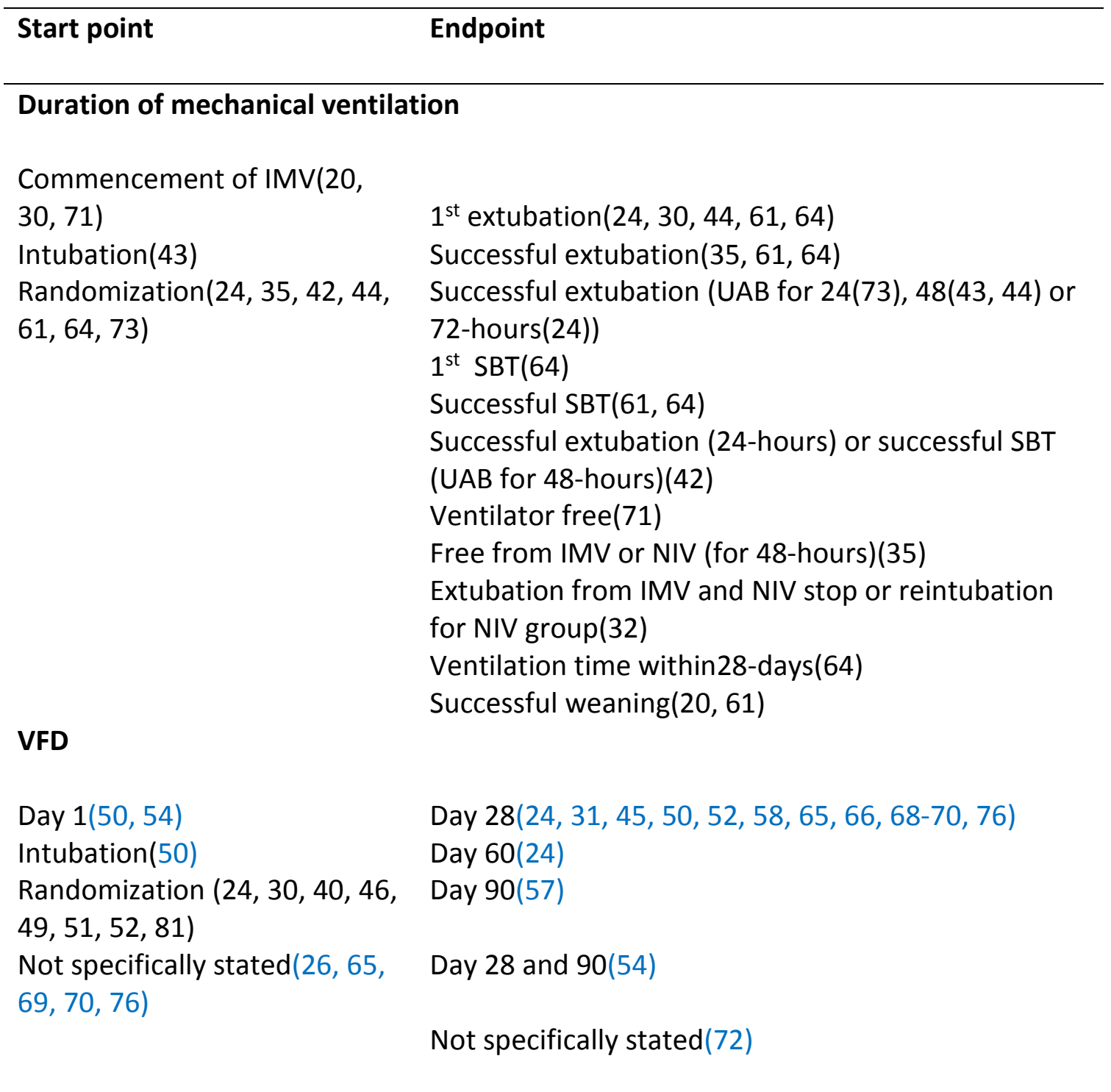

Key: IMV, invasive mechanical ventilation; NIV, noninvasive mechanical ventilation; SBT, spontaneous breathing trial; $U A B$, unassisted breathing. Some trials measured more than one endpoint. 
Table 3 Start and end point variability for ventilation outcomes in 12 ventilation trials

\begin{tabular}{|c|c|}
\hline Start point & Endpoint \\
\hline \multicolumn{2}{|c|}{ Duration of mechanical ventilation } \\
\hline $\begin{array}{l}\text { Commencement of IMV }(20 \text {, } \\
\text { 30) }\end{array}$ & $1^{\text {st }}$ extubation $(30,61,64)$ \\
\hline Intubation $(43,61)$ & Successful extubation(61) \\
\hline \multirow[t]{5}{*}{ Randomization $(39,76,77)$} & Extubation or a trache mask for 48 -hours $(43,44)$ \\
\hline & $\begin{array}{l}\text { Extubation from IMV and NIV stop or reintubation } \\
\text { for NIV group(32) }\end{array}$ \\
\hline & $1^{\text {st }} \mathrm{SBT}(32)$ \\
\hline & Successful SBT(32) \\
\hline & Successful weaning(20) \\
\hline \multicolumn{2}{|l|}{ VFD } \\
\hline $\begin{array}{l}\text { Intubation(68) } \\
\text { Randomization(31,68) }\end{array}$ & Day $28(31,68)$ \\
\hline
\end{tabular}

Key: IMV, invasive mechanical ventilation; NIV, noninvasive mechanical ventilation; SBT, spontaneous breathing trial. Some trials measured more than one start and endpoint. 


\section{References}

1. Glasziou PP, Sanders SL. Investigating causes of heterogeneity in systematic reviews. Statistics in medicine. 2002;21(11):1503-11.

2. Williamson PR, Altman DG, Blazeby JM, Clarke M, Devane D, Gargon E, et al. Developing core outcome sets for clinical trials: issues to consider. Trials. 2012;13:132.

3. Blackwood B, Alderdice F, Burns KE, Cardwell CR, Lavery G, O'Halloran P. Protocolized versus non-protocolized weaning for reducing the duration of mechanical ventilation in critically ill adult patients. Cochrane Database of Systematic Reviews. 2010(5):CD006904.

4. Blackwood B, Murray M, Chisakuta A, Cardwell CR, P OH. Protocolized versus nonprotocolized weaning for reducing the duration of mechanical ventilation in critically ill paediatric patients. Cochrane Database of Systematic Reviews 2013:In press.

5. CONSORT. Available from: http://www.consort-statement.org/.

6. World Health Organisation. The WHO Registry Network. Available from: http://www.who.int/ictrp/network/en/.

7. Chan AW, Tetzlaff JM, Gotzsche PC, Altman DG, Mann H, Berlin JA, et al. SPIRIT 2013 explanation and elaboration: guidance for protocols of clinical trials. BMJ (Clinical research ed). 2013;346:e7586.

8. Zarin DA, Tse T, Williams RJ, Califf RM, Ide NC. The ClinicalTrials.gov results database--update and key issues. The New England journal of medicine. 2011;364(9):852-60.

9. Chan AW, Hrobjartsson A, Haahr MT, Gotzsche PC, Altman DG. Empirical evidence for selective reporting of outcomes in randomized trials: comparison of protocols to published articles. JAMA : the journal of the American Medical Association. 2004;291(20):2457-65.

10. Chan AW, Krleza-Jeric K, Schmid I, Altman DG. Outcome reporting bias in randomized trials funded by the Canadian Institutes of Health Research. CMAJ : Canadian Medical Association journal = journal de l'Association medicale canadienne. 2004;171(7):735-40.

11. Clarke M. Standardising outcomes for clinical trials and systematic reviews. Trials. 2007;8:39.

12. COMET. The COMET database. Available from: http://www.comet-initiative.org/.

13. Agus MS, Steil GM, Wypij D, Costello JM, Laussen PC, Langer M, et al. Tight glycemic control versus standard care after pediatric cardiac surgery. The New England journal of medicine. 2012;367(13):1208-19.

14. Bellomo R, Cass A, Cole L, Finfer S, Gallagher M, Lo S, et al. Intensity of continuous renalreplacement therapy in critically ill patients. The New England journal of medicine.

2009;361(17):1627-38.

15. Bjelland TW, Dale O, Kaisen K, Haugen BO, Lydersen S, Strand K, et al. Propofol and remifentanil versus midazolam and fentanyl for sedation during therapeutic hypothermia after cardiac arrest: a randomised trial. Intensive care medicine. 2012;38(6):959-67.

16. Blot F, Similowski T, Trouillet IL, Chardon P, Korach JM, Costa MA, et al. Early tracheotomy versus prolonged endotracheal intubation in unselected severely ill ICU patients. Intensive care medicine. 2008;34(10):1779-87.

17. Boussekey N, Chiche A, Faure K, Devos P, Guery B, d'Escrivan T, et al. A pilot randomized study comparing high and low volume hemofiltration on vasopressor use in septic shock. Intensive care medicine. 2008;34(9):1646-53.

18. Brunkhorst FM, Engel C, Bloos F, Meier-Hellmann A, Ragaller M, Weiler N, et al. Intensive insulin therapy and pentastarch resuscitation in severe sepsis. The New England journal of medicine. 2008;358(2):125-39.

19. Brunkhorst FM, Oppert M, Marx G, Bloos F, Ludewig K, Putensen C, et al. Effect of empirical treatment with moxifloxacin and meropenem vs meropenem on sepsis-related organ dysfunction in patients with severe sepsis: a randomized trial. JAMA : the journal of the American Medical Association. 2012;307(22):2390-9. 
20. Bucknall TK, Manias E, Presneill JJ. A randomized trial of protocol-directed sedation management for mechanical ventilation in an Australian intensive care unit. Critical care medicine. 2008;36(5):1444-50.

21. Carcillo JA, Dean JM, Holubkov R, Berger J, Meert KL, Anand KJ, et al. The randomized comparative pediatric critical illness stress-induced immune suppression (CRISIS) prevention trial. Pediatric critical care medicine : a journal of the Society of Critical Care Medicine and the World Federation of Pediatric Intensive and Critical Care Societies. 2012;13(2):165-73.

22. Casaer MP, Mesotten D, Hermans G, Wouters PJ, Schetz M, Meyfroidt G, et al. Early versus late parenteral nutrition in critically ill adults. The New England journal of medicine. 2011;365(6):506-17.

23. Craig TR, Duffy MJ, Shyamsundar M, McDowell C, O'Kane CM, Elborn JS, et al. A randomized clinical trial of hydroxymethylglutaryl- coenzyme a reductase inhibition for acute lung injury (The HARP Study). American journal of respiratory and critical care medicine. 2011;183(5):620-6.

24. Mekontso Dessap A, Roche-Campo F, Kouatchet A, Tomicic V, Beduneau G, Sonneville R, et al. Natriuretic peptide-driven fluid management during ventilator weaning: a randomized controlled trial. American journal of respiratory and critical care medicine. 2012;186(12):1256-63.

25. Davies AR, Morrison SS, Bailey MJ, Bellomo R, Cooper DJ, Doig GS, et al. A multicenter, randomized controlled trial comparing early nasojejunal with nasogastric nutrition in critical illness. Critical care medicine. 2012;40(8):2342-8.

26. De Backer D, Biston P, Devriendt J, Madl C, Chochrad D, Aldecoa C, et al. Comparison of dopamine and norepinephrine in the treatment of shock. The New England journal of medicine. 2010;362(9):779-89.

27. Duman N, Tuzun F, Sutcuoglu S, Yesilirmak CD, Kumral A, Ozkan H. Impact of volume guarantee on synchronized ventilation in preterm infants: a randomized controlled trial. Intensive care medicine. 2012;38(8):1358-64.

28. Fernandez R, Trenchs X, Klamburg J, Castedo J, Serrano JM, Besso G, et al. Prone positioning in acute respiratory distress syndrome: a multicenter randomized clinical trial. Intensive care medicine. 2008;34(8):1487-91.

29. Finfer S, Chittock DR, Su SY, Blair D, Foster D, Dhingra V, et al. Intensive versus conventional glucose control in critically ill patients. The New England journal of medicine. 2009;360(13):1283-97. 30. Foronda FK, Troster EJ, Farias JA, Barbas CS, Ferraro AA, Faria LS, et al. The impact of daily evaluation and spontaneous breathing test on the duration of pediatric mechanical ventilation: a randomized controlled trial. Critical care medicine. 2011;39(11):2526-33.

31. Girard TD, Kress JP, Fuchs BD, Thomason JW, Schweickert WD, Pun BT, et al. Efficacy and safety of a paired sedation and ventilator weaning protocol for mechanically ventilated patients in intensive care (Awakening and Breathing Controlled trial): a randomised controlled trial. Lancet. 2008;371(9607):126-34.

32. Girault C, Bubenheim M, Abroug F, Diehl JL, Elatrous S, Beuret P, et al. Noninvasive ventilation and weaning in patients with chronic hypercapnic respiratory failure: a randomized multicenter trial. American journal of respiratory and critical care medicine. 2011;184(6):672-9. 33. Hough CL, Steinberg KP, Taylor Thompson B, Rubenfeld GD, Hudson LD. Intensive care unitacquired neuromyopathy and corticosteroids in survivors of persistent ARDS. Intensive care medicine. 2009;35(1):63-8.

34. Jack T, Boehne M, Brent BE, Hoy L, Koditz $H$, Wessel A, et al. In-line filtration reduces severe complications and length of stay on pediatric intensive care unit: a prospective, randomized, controlled trial. Intensive care medicine. 2012;38(6):1008-16.

35. Jakob SM, Ruokonen E, Grounds RM, Sarapohja T, Garratt C, Pocock SJ, et al. Dexmedetomidine vs midazolam or propofol for sedation during prolonged mechanical ventilation: two randomized controlled trials. JAMA : the journal of the American Medical Association. 2012;307(11):1151-60. 
36. Jansen TC, van Bommel J, Schoonderbeek FJ, Sleeswijk Visser SJ, van der Klooster JM, Lima AP, et al. Early lactate-guided therapy in intensive care unit patients: a multicenter, open-label, randomized controlled trial. American journal of respiratory and critical care medicine.

2010;182(6):752-61.

37. Knight DJ, Gardiner D, Banks A, Snape SE, Weston VC, Bengmark S, et al. Effect of synbiotic therapy on the incidence of ventilator associated pneumonia in critically ill patients: a randomised, double-blind, placebo-controlled trial. Intensive care medicine. 2009;35(5):854-61.

38. Kollef MH, Afessa B, Anzueto A, Veremakis C, Kerr KM, Margolis BD, et al. Silver-coated endotracheal tubes and incidence of ventilator-associated pneumonia: the NASCENT randomized trial. JAMA : the journal of the American Medical Association. 2008;300(7):805-13.

39. Gupta K, Gupta VK, Jayashree M, Singhi S. Randomized controlled trial of interrupted versus continuous sedative infusions in ventilated children. Pediatric critical care medicine : a journal of the Society of Critical Care Medicine and the World Federation of Pediatric Intensive and Critical Care Societies. 2012;13(2):131-5.

40. Lacherade JC, De Jonghe B, Guezennec P, Debbat K, Hayon J, Monsel A, et al. Intermittent subglottic secretion drainage and ventilator-associated pneumonia: a multicenter trial. American journal of respiratory and critical care medicine. 2010;182(7):910-7.

41. Manzanares W, Biestro A, Torre MH, Galusso F, Facchin G, Hardy G. High-dose selenium reduces ventilator-associated pneumonia and illness severity in critically ill patients with systemic inflammation. Intensive care medicine. 2011;37(7):1120-7.

42. Meade MO, Cook DJ, Guyatt GH, Slutsky AS, Arabi YM, Cooper DJ, et al. Ventilation strategy using low tidal volumes, recruitment maneuvers, and high positive end-expiratory pressure for acute lung injury and acute respiratory distress syndrome: a randomized controlled trial. JAMA : the journal of the American Medical Association. 2008;299(6):637-45.

43. Mehta S, Burry L, Martinez-Motta JC, Stewart TE, Hallett D, McDonald E, et al. A randomized trial of daily awakening in critically ill patients managed with a sedation protocol: a pilot trial. Critical care medicine. 2008;36(7):2092-9.

44. Mehta S, Burry L, Cook D, Fergusson D, Steinberg M, Granton J, et al. Daily sedation interruption in mechanically ventilated critically ill patients cared for with a sedation protocol: a randomized controlled trial. JAMA : the journal of the American Medical Association.

2012;308(19):1985-92.

45. Mercat A, Richard JC, Vielle B, Jaber S, Osman D, Diehl JL, et al. Positive end-expiratory pressure setting in adults with acute lung injury and acute respiratory distress syndrome: a randomized controlled trial. JAMA : the journal of the American Medical Association. 2008;299(6):646-55.

46. Mesnil M, Capdevila X, Bringuier S, Trine PO, Falquet $\mathrm{Y}$, Charbit J, et al. Long-term sedation in intensive care unit: a randomized comparison between inhaled sevoflurane and intravenous propofol or midazolam. Intensive care medicine. 2011;37(6):933-41.

47. Morrow LE, Kollef MH, Casale TB. Probiotic prophylaxis of ventilator-associated pneumonia: a blinded, randomized, controlled trial. American journal of respiratory and critical care medicine. 2010;182(8):1058-64.

48. Myburgh JA, Finfer S, Bellomo R, Billot L, Cass A, Gattas D, et al. Hydroxyethyl starch or saline for fluid resuscitation in intensive care. The New England journal of medicine. 2012;367(20):1901-11.

49. Navalesi P, Frigerio P, Moretti MP, Sommariva M, Vesconi S, Baiardi P, et al. Rate of reintubation in mechanically ventilated neurosurgical and neurologic patients: evaluation of a systematic approach to weaning and extubation. Critical care medicine. 2008;36(11):2986-92. 50. Nguyen NQ, Besanko LK, Burgstad C, Bellon M, Holloway RH, Chapman M, et al. Delayed enteral feeding impairs intestinal carbohydrate absorption in critically ill patients. Critical care medicine. 2012;40(1):50-4. 
51. Nseir S, Zerimech F, Fournier C, Lubret R, Ramon P, Durocher A, et al. Continuous control of tracheal cuff pressure and microaspiration of gastric contents in critically ill patients. American journal of respiratory and critical care medicine. 2011;184(9):1041-7.

52. Paine R, 3rd, Standiford TJ, Dechert RE, Moss M, Martin GS, Rosenberg AL, et al. A randomized trial of recombinant human granulocyte-macrophage colony stimulating factor for patients with acute lung injury. Critical care medicine. 2012;40(1):90-7.

53. Pandharipande PP, Pun BT, Herr DL, Maze M, Girard TD, Miller RR, et al. Effect of sedation with dexmedetomidine vs lorazepam on acute brain dysfunction in mechanically ventilated patients: the MENDS randomized controlled trial. JAMA : the journal of the American Medical Association. 2007;298(22):2644-53.

54. Papazian L, Forel JM, Gacouin A, Penot-Ragon C, Perrin G, Loundou A, et al. Neuromuscular blockers in early acute respiratory distress syndrome. The New England journal of medicine. 2010;363(12):1107-16.

55. Patman S, Jenkins S, Stiller K. Physiotherapy does not prevent, or hasten recovery from, ventilator-associated pneumonia in patients with acquired brain injury. Intensive care medicine. 2009;35(2):258-65.

56. Payen JF, Dupuis C, Trouve-Buisson T, Vinclair M, Broux C, Bouzat P, et al. Corticosteroid after etomidate in critically ill patients: a randomized controlled trial. Critical care medicine. 2012;40(1):29-35.

57. Perner A, Haase N, Guttormsen AB, Tenhunen J, Klemenzson G, Aneman A, et al. Hydroxyethyl starch 130/0.42 versus Ringer's acetate in severe sepsis. The New England journal of medicine. 2012;367(2):124-34.

58. Rice TW, Mogan S, Hays MA, Bernard GR, Jensen GL, Wheeler AP. Randomized trial of initial trophic versus full-energy enteral nutrition in mechanically ventilated patients with acute respiratory failure. Critical care medicine. 2011;39(5):967-74.

59. Riker RA, Shehabi Y, Bokesch PM, Ceraso D, Wisemandle W, Koura F, et al. Dexmedetomidine vs Midazolam for Sedation of Critically III Patients: A Randomized Trial

Journal of American Medical Association. 2009;301(5):489-99.

60. Rohm KD, Wolf MW, Schollhorn T, Schellhaass A, Boldt J, Piper SN. Short-term sevoflurane sedation using the Anaesthetic Conserving Device after cardiothoracic surgery. Intensive care medicine. 2008;34(9):1683-9.

61. Rose L, Presneill JJ, Johnston L, Cade JF. A randomised, controlled trial of conventional versus automated weaning from mechanical ventilation using SmartCare/PS. Intensive care medicine. 2008;34(10):1788-95.

62. Ruokonen E, Parviainen I, Jakob SM, Nunes S, Kaukonen M, Shepherd ST, et al. Dexmedetomidine versus propofol/midazolam for long-term sedation during mechanical ventilation. Intensive care medicine. 2009;35(2):282-90.

63. Russell JA, Walley KR, Singer J, Gordon AC, Hebert PC, Cooper DJ, et al. Vasopressin versus norepinephrine infusion in patients with septic shock. The New England journal of medicine. 2008;358(9):877-87.

64. Schadler D, Engel C, Elke G, Pulletz S, Haake N, Frerichs I, et al. Automatic control of pressure support for ventilator weaning in surgical intensive care patients. American journal of respiratory and critical care medicine. 2012;185(6):637-44.

65. Schweickert WD, Pohlman MC, Pohlman AS, Nigos C, Pawlik AJ, Esbrook CL, et al. Early physical and occupational therapy in mechanically ventilated, critically ill patients: a randomised controlled trial. Lancet. 2009;373(9678):1874-82.

66. Gao Smith F, Perkins GD, Gates S, Young D, McAuley DF, Tunnicliffe W, et al. Effect of intravenous beta-2 agonist treatment on clinical outcomes in acute respiratory distress syndrome (BALTI-2): a multicentre, randomised controlled trial. Lancet. 2012;379(9812):229-35. 
67. Spies C, Macguill M, Heymann A, Ganea C, Krahne D, Assman A, et al. A prospective, randomized, double-blind, multicenter study comparing remifentanil with fentanyl in mechanically ventilated patients. Intensive care medicine. 2011;37(3):469-76.

68. Strom T, Martinussen T, Toft P. A protocol of no sedation for critically ill patients receiving mechanical ventilation: a randomised trial. Lancet. 2010;375(9713):475-80.

69. Taccone P, Pesenti A, Latini R, Polli F, Vagginelli F, Mietto $C$, et al. Prone positioning in patients with moderate and severe acute respiratory distress syndrome: a randomized controlled trial. JAMA : the journal of the American Medical Association. 2009;302(18):1977-84.

70. Talmor D, Sarge T, Malhotra A, O'Donnell CR, Ritz R, Lisbon A, et al. Mechanical ventilation guided by esophageal pressure in acute lung injury. The New England journal of medicine. 2008;359(20):2095-104.

71. Templeton M, Palazzo MG. Chest physiotherapy prolongs duration of ventilation in the critically ill ventilated for more than 48 hours. Intensive care medicine. 2007;33(11):1938-45.

72. Terragni PP, Antonelli M, Fumagalli R, Faggiano C, Berardino M, Pallavicini FB, et al. Early vs late tracheotomy for prevention of pneumonia in mechanically ventilated adult ICU patients: a randomized controlled trial. JAMA : the journal of the American Medical Association.

2010;303(15):1483-9.

73. Thomas NJ, Guardia CG, Moya FR, Cheifetz IM, Markovitz B, Cruces P, et al. A pilot, randomized, controlled clinical trial of lucinactant, a peptide-containing synthetic surfactant, in infants with acute hypoxemic respiratory failure. Pediatric critical care medicine : a journal of the Society of Critical Care Medicine and the World Federation of Pediatric Intensive and Critical Care Societies. 2012;13(6):646-53.

74. Treggiari MM, Romand JA, Yanez ND, Deem SA, Goldberg J, Hudson L, et al. Randomized trial of light versus deep sedation on mental health after critical illness. Critical care medicine. 2009;37(9):2527-34.

75. Tsangaris I, Galiatsou E, Kostanti E, Nakos G. The effect of exogenous surfactant in patients with lung contusions and acute lung injury. Intensive care medicine. 2007;33(5):851-5.

76. Vaschetto R, Turucz E, Dellapiazza F, Guido S, Colombo D, Cammarota G, et al. Noninvasive ventilation after early extubation in patients recovering from hypoxemic acute respiratory failure: a single-centre feasibility study. Intensive care medicine. 2012;38(10):1599-606.

77. Welzing L, Oberthuer A, Junghaenel S, Harnischmacher U, Stutzer H, Roth B.

Remifentanil/midazolam versus fentanyl/midazolam for analgesia and sedation of mechanically ventilated neonates and young infants: a randomized controlled trial. Intensive care medicine. 2012;38(6):1017-24.

78. Xirouchaki N, Kondili E, Vaporidi K, Xirouchakis G, Klimathianaki M, Gavriilidis G, et al. Proportional assist ventilation with load-adjustable gain factors in critically ill patients: comparison with pressure support. Intensive care medicine. 2008;34(11):2026-34.

79. Egleston BL, Scharfstein DO, Freeman EE, West SK. Causal inference for non-mortality outcomes in the presence of death. Biostatistics (Oxford, England). 2007;8(3):526-45.

80. Sevransky JE, Checkley W, Martin GS. Critical care trial design and interpretation: A primer. Critical care medicine. 2010;38(9):1882-9 10.097/CCM.0b013e3181eae226.

81. Lau B, Cole SR, Gange SJ. Competing risk regression models for epidemiologic data. American journal of epidemiology. 2009;170(2):244-56.

82. Checkley W, Brower RG, Munoz A. Inference for mutually exclusive competing events through a mixture of generalized gamma distributions. Epidemiology (Cambridge, Mass). 2010;21(4):557-65.

83. Varadhan R, Weiss CO, Segal JB, Wu AW, Scharfstein D, Boyd C. Evaluating health outcomes in the presence of competing risks: a review of statistical methods and clinical applications. Medical care. 2010;48(6 Suppl):S96-105.

84. Blackwood B, Wilson-Barnett J, Trinder J. Protocolized weaning from mechanical ventilation: ICU physicians' views. J Adv Nurs. 2004;48(1):26-34. 
85. Krishnan JA MD, Robeson C, et al. . A prospective, controlled trial of a protocol-based strategy to discontinue mechanical ventilation. American journal of respiratory and critical care medicine. 2004;169(673-678).

86. Rubenfeld GD, Angus DC, Pinsky MR, Curtis JR, Connors AF, Jr., Bernard GR. Outcomes research in critical care: results of the American Thoracic Society Critical Care Assembly Workshop on Outcomes Research. The Members of the Outcomes Research Workshop. American journal of respiratory and critical care medicine. 1999;160(1):358-67.

87. Spragg RG, Bernard GR, Checkley W, Curtis JR, Gajic O, Guyatt G, et al. Beyond mortality: future clinical research in acute lung injury. American journal of respiratory and critical care medicine. 2010;181(10):1121-7.

88. Needham DM, Davidson J, Cohen H, Hopkins RO, Weinert C, Wunsch H, et al. Improving long-term outcomes after discharge from intensive care unit: report from a stakeholders' conference. Critical care medicine. 2012;40(2):502-9.

89. Needham DM, Dinglas VD, Bienvenu OJ, Colantuoni E, Wozniak AW, Rice TW, et al. One year outcomes in patients with acute lung injury randomised to initial trophic or full enteral feeding: prospective follow-up of EDEN randomised trial. BMJ (Clinical research ed). 2013;346:f1532.

90. Needham DM, Dinglas VD, Morris PE, Jackson JC, Hough CL, Mendez-Tellez PA, et al. Physical and cognitive performance of patients with acute lung injury 1 year after initial trophic versus full enteral feeding. EDEN trial follow-up. American journal of respiratory and critical care medicine. 2013;188(5):567-76.

91. Peek GJ, Mugford M, Tiruvoipati R, Wilson A, Allen E, Thalanany MM, et al. Efficacy and economic assessment of conventional ventilatory support versus extracorporeal membrane oxygenation for severe adult respiratory failure (CESAR): a multicentre randomised controlled trial. Lancet. 2009;374(9698):1351-63. 